\section{REFERENCES}

1. Kraus MD, Fleming MD, Vonderheide RH. The spleen as a diagnostic specimen: A review of 10 years' experience at two tertiary care institutions. Cancer 2001;91:2001-2009.

2. Rokitansky K, editor. Abnormalities of the spleen. Lehrbuch der Pathologischen Anatomie, 3rd edition. Vienna: Wilhelm Braumuller. $1861 ;$ p. 3.

3. Silverman ML, LiVolsi VA. Splenic hamartoma. Am J Clin Pathol 1978;70:224-229.

4. Iozzo RV, Haas JE, Chard RL. Symptomatic splenic hemartoma: A report of two cases and review of the literature. Pediatrics 1980 66:261-265

5. Bender BL, Yunis EJ. Splenic involvement in tuberous sclerosis. Report of three cases. Virchows Arch A Pathol Anat Histol 1981: 391:363-369.

6. Darden JW, Teeslink R, Parrish A. Hamartoma of the spleen: A manifestation of tuberous sclerosis. Am Surg 1975;41:564-566.

7. Abbott RM, Levy AD, Aguilera NS, et al. From the archives of the AFIP: Primary vascular neoplasms of the spleen: Radiologicpathologic correlation. Radiographics 2004;24:1137-1163.

8. Cheuk W, Lee AK, Arora N, et al. Splenic hamartoma with bizarre stromal cells. Am J Surg Pathol 2005;29:109-114.

9. Lee SH. Fine-needle aspiration cytology of splenic hamartoma. Diagn Cytopathol 2003;28:82-85.

10. Kubota R, Yamada S, Kubota K, et al. Intratumoral distribution of fluorine-18-fluorodeoxyglucose in vivo: High accumulation in macrophages and granulation tissues studied by microautoradiography. J Nucl Med 1992;33:1972-1980.
11. Metser U, Even-Sapir E. The role of 18F-FDG PET/CT in the evaluation of solid splenic masses. Semin Ultrasound CT MR 2006;27:420-425.

12. Metser U, Miller E, Kessler A, et al. Solid splenic masses: Evaluation with 18F-FDG PET/CT. J Nucl Med 2005;46: $52-59$.

13. Even-Sapir E, Lievshitz G, Perry C, et al. Fluorine-18 fluorodeoxyglucose PET/CT patterns of extranodal involvement in patients with Non-Hodgkin lymphoma and Hodgkin disease. Radiol Clin North Am 2007;45:697-709, vii.

14. Donner LR, Marcussen S, Dobin SM. A clonal dic $(16 ; 21)$ (p13.1;p11.2)del(16)(q11.1), with gains of several chromosomes and monosomy 21, in a case of splenic hamartoma: Evidence for its neoplastic, not hamartomatous, origin. Cancer Genet Cytogenet 2005; 157:160-163.

15. Elsheikh TM, Herzberg AJ, Silverman JF. Fine-needle aspiration cytology of metastatic malignancies involving unusual sites. Am J Clin Pathol 1997;108:S12-S21.

16. Silverman JF, Geisinger KR, Raab SS, et al. Fine needle aspiration biopsy of the spleen in the evaluation of neoplastic disorders. Acta Cytol 1993;37:158-162.

17. Muraca S, Chait PG, Connolly BL, et al. US-guided core biopsy of the spleen in children. Radiology 2001;218:200-206.

18. Kimber C, Spitz L, Drake D, et al. Elective partial splenectomy in childhood. J Pediatr Surg 1998;33:826-829.

19. Hery G, Becmeur F, Mefat L, et al. Laparoscopic partial splenectomy: Indications and results of a multicenter retrospective study. Surg Endosc 2008;22:45-49.

\title{
Pediatric Duodenal Cancer and Biallelic Mismatch Repair Gene Mutations
}

\author{
Sumita Roy, $\mathrm{MD},{ }^{1} *$ Leon Raskin, $\mathrm{PhD}^{2}{ }^{2}$ Victoria M. Raymond, $\mathrm{Ms}^{2}{ }^{2}$ Stephen N. Thibodeau, $\mathrm{PhD},{ }^{3}$ \\ Rajen J. Mody, $\mathrm{MD}^{1}{ }^{1}$ and Stephen B. Gruber, $\mathrm{MD}$, $\mathrm{PhD}, \mathrm{MPH}^{2,4,5 *}$
}

Gastrointestinal malignancies are extremely rare in the pediatric population, and duodenal cancers represent an even more unusual entity. Intestinal cancers in young adults and children have been observed to be associated with functional deficiencies of the mismatch repair (MMR) system causing a cancer-predisposition syndrome. We report the case of a 16-year-old female with duodenal adenocarcinoma and past history of medulloblastoma found to have a novel germline bialleleic truncating mutation (c. [949C >T]+ [949C > T] ) of the PMS2 gene. Pediatr Blood Cancer 2009;53:116120. () 2009 Wiley-Liss, Inc.

Key words: biallelic; children and young adults; duodenal adenocarcinoma; mismatch repair

\section{INTRODUCTION}

Gastrointestinal malignancies in children present challenging management issues and are often suggestive of inherited susceptibility to cancer. DNA mismatch repair (MMR) genes, MLH1, MSH2, MSH6, and PMS2 maintain genome integrity by correcting DNA replication errors [1]. Defective MMR causes microsatellite instability (MSI) (errors in length of microsatellites or repeated sequences of DNA), a hallmark of MMR deficiency. Germline heterozygous mutations in MMR genes results in Lynch syndrome or Hereditary Non-Polyposis Colorectal Cancer (HNPCC), an autosomal dominant cancer susceptibility syndrome with increased risk for developing colorectal and endometrial malignancies. Within the last decade there has been mounting evidence for an inherited cancer syndrome resulting from germline biallelic mutations in MMR genes which has been alternately referred to
Additional Supporting Information may be found in the online version of this article.

${ }^{1}$ Division of Pediatric Hematology-Oncology, Dept. of Pediatrics, University of Michigan Health System, Ann Arbor, Michigan; ${ }^{2}$ Department of Internal Medicine, University of Michigan Medical School, Ann Arbor, Michigan; ${ }^{3}$ Department of Laboratory Medicine and Pathology, Mayo Clinic, Rochester, Minnesota; ${ }^{4}$ Department of Epidemiology, University of Michigan School of Public Health, Ann Arbor, Michigan; ${ }^{5}$ Department of Human Genetics, University of Michigan Medical School, Ann Arbor, Michigan

*Correspondence to: Sumita Roy and Stephen B. Gruber, Department of Pediatrics, Division of Pediatric Hematology-Oncology, University of Michigan Health System, 1500 East Medical Center Drive, L2110 Women's Hospital, Ann Arbor, MI 48109-0238.

E-mail: sumitar@med.umich.edu; sgruber@umich.edu

Received 15 October 2008; Accepted 6 January 2009 
as childhood cancer syndrome (CCS), MMR-deficiency syndrome (MMR-D) and constitutional MMR deficiency (CMMR-D) [2-4]. This syndrome results from complete deficiency of MMR function and differs from HNPCC in the tumor spectrum, age of onset and presence of café-au-lait macules (CALM).

\section{CASE}

A 16-year-old female of Syrian descent, with multiple CALM was diagnosed with a moderately differentiated adenocarcinoma arising in the ampulla and invading the pancreas, with metastases to 6/39 lymph nodes. She underwent a Whipple procedure and received adjuvant radiation therapy along with continuous 5-FU (5fluoro-uracil) infusion for 6 weeks, followed by eight cycles of modified FOLFOX $6\left(85 \mathrm{mg} / \mathrm{m}^{2}\right.$ of oxaliplatin and $400 \mathrm{mg} / \mathrm{m}^{2}$ Leucovorin, followed by $400 \mathrm{mg} / \mathrm{m}^{2} 5-\mathrm{FU}$ bolus and $2,400 \mathrm{mg} / \mathrm{m}^{2}$ 5-FU infusion for $46 \mathrm{hr}$ ). At the conclusion of chemotherapy, imaging showed a new $2 \mathrm{~cm}$ sigmoid mass. Laparoscopic sigmoid resection revealed an adenoma.

Her past history is significant for medulloblastoma diagnosed at age 8 , treated with surgery and radiation. Family history is significant for parental consanguinity (Fig. 1A) and diagnosis of precursor T-cell acute lymphoblastic leukemia (ALL) in younger brother (IV.3) at age 5, who died at age 6. The history of consanguinity in siblings with medulloblastoma and leukemia had prompted a cancer genetics consultation 7 years ago in IV.3, who also had CALM (largest measuring $4.5 \mathrm{~cm}$ ) and several dysmorphic features. His workup included evaluation for mutations in $M L H 1$ and $M S H 2$ based on reports in the literature documenting hematologic malignancies as a feature of MMR deficiency $[5,6]$.
No mutations in $M L H 1$ and $M S H 2$ were identified and tissue was insufficient for immunohistochemistry (IHC) and MSI analysis. The second diagnosis of duodenal cancer in the patient (IV.1) led to further suspicion of MMR-D, and genetic counseling, molecular diagnostic workup and enrollment in an IRB-approved cancer genetics registry was offered.

\section{MOLECULAR ANALYSIS}

Duodenal carcinoma tissue analysis demonstrated high degree of MSI in 10/10 markers tested and IHC demonstrated absent PMS2 expression in tumor and normal tissue, with intact expression of MLH1, MSH2, and MSH6 [7]. Blood samples of IV.1 and her parents were tested for PMS2 mutations on a research protocol [8]. After initial identification of the mutation, confirmatory testing was performed in research and clinical laboratories at the University of Michigan. PMS2 exon 9 was amplified using PCR primers $5^{\prime}$ GGCTGGGAACATTTGTCATT- $3^{\prime}$ and $5^{\prime}$-TGCCAATGGAACTTACCTGA- $3^{\prime}$, purified and genotyped by direct sequencing on an ABI 3730 sequencer. DNA sequence analysis (GenBank RefSeqNM_000535.5) using Mutation Surveyor software, revealed a unique cytosine to thymine transition at coding nucleotide position 949 (949C $>$ T) in the $P M S 2$ exon 9 resulting in a codon change from glutamine to a premature stop codon at amino acid 317 (Q317X) (Fig. 1C). Consistent with the expectation from a consanguineous family, IV.1 was homozygous for the mutation and both parents were heterozygous for the same mutant allele. Analysis of IV.3's normal and tumor tissue was hindered due to poor tissue quality, but clearly demonstrated at least one mutant allele. The family declined genetic testing of the other siblings.
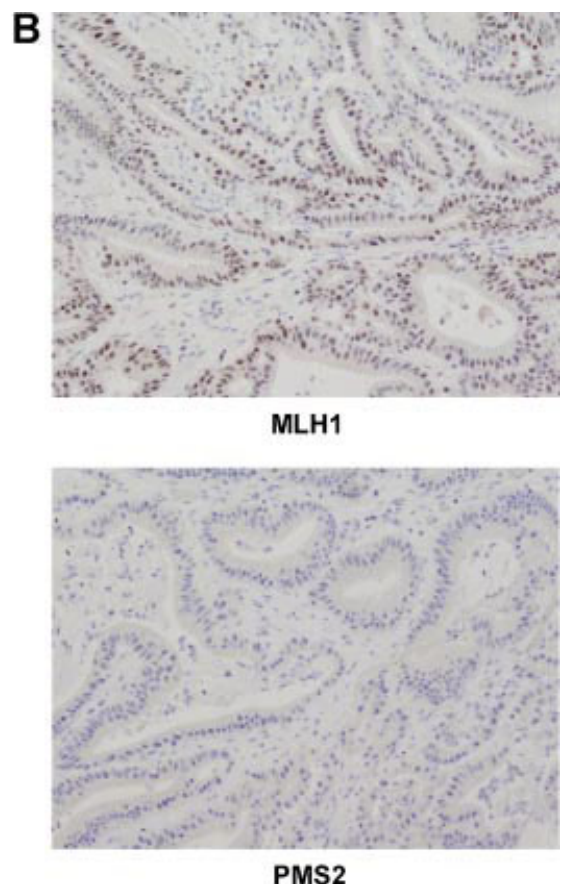

Fig. 1. Autosomal recessive susceptibility to cancer in a consanguineous Syrian family due to a homozygous mutation of $P M S 2$. A: Pedigree showing medulloblastoma at age 8 and duodenal carcinoma at age 16 in IV.1 and Pre T-cell ALL at age 5 in IV.3, whose parents are first cousins. B: Immunohistochemistry showing intact expression of MHL1 (top) and absent expression of PMS2 (bottom). C: Sequencing chromatograms show a heterozygous mutation of PMS2 949C $>$ T (Q317X) within exon 9 in both parents (who are unaffected), and a homozygous mutation in the affected 16-year-old female. [Color figure can be viewed in the online issue, which is available at www.interscience.wiley.com.] 







\section{DISCUSSION}

Duodenal cancers are extremely rare with median age of diagnosis in the sixth decade of life. A systematic literature search for early onset duodenal cancers revealed five other cases (Table I), four of which had germline biallelic MMR mutations [8-12]. A comprehensive literature review through PubMed revealed 50 families with germline biallelic MMR mutations (Supplemental Tables I and II). The present case is cited in two other reviews [4,8], and here we present the full clinical details of this case and review the implications of a diagnosis of MMR-D.

MMR-D phenotype is seen in homozygotes or compound heterozygotes and absence of a family history of cancer does not diminish its likelihood. Biallelic mutations in PMS2 accounted for majority of cases in families with MMR-D (25/50 families, 50\%), while $M L H 1$ and MSH6 each accounted for $20 \%$ of families, and MSH2 accounted for $10 \%$ of families. Onset of tumors is as early as the first decade of life and the tumor spectrum primarily comprises of gastrointestinal (colorectal and small intestinal tumors), brain (glioblastoma, astrocytoma, medulloblastoma, PNET), and hematological malignancies (ALL and non-Hodgkin lymphoma, T-cell type). Colorectal cancers were reported in 37 individuals in 27/50 (54\%) families (median age: 17 years); small intestinal cancers in 7 individuals in 5/50 (10\%) families (median age: 17 years); brain tumors in 40 individuals in 29/50 (58\%) families (median age: 8 years) and hematolological malignancies in 29 individuals in 19/ 50 (38\%) families (median age: 5 years). Other malignancies reported were: 5 cases of endometrial cancer (median age: 24 years), one case of ureter/renal pelvis cancer at age 15, two cases of rhabdomyosarcoma (ages 4 and 18), one case of Wilms tumor (age 4 ), one case of infantile myofibromatosis (age 1), one case of neuroblastoma (age 13), one case of breast cancer (age 35), one case of ovarian neuroectodermal tumor (age 21) and one case of sarcoma (age 65). Thirty two of the 84 (34.2\%) patients developed more than one primary tumor. Survival data reported in 64 patients revealed that 38 patients $(59.3 \%)$ died of their disease at median age of 10 years.

Multiple CALM have been reported in 35/50 (70\%) families, with only one patient having a germline NF-1 mutation [13]. However, NF1 may be a mutational target of MMR-deficiency [5,13,14]. Hypopigmentation, immunodeficiencies and autoimmune diseases have been reported with biallelic MSH6 mutations [15-18]. CALM have not been reported in any heterozygous carriers. Although the chromatogram of IV.3 suggests that he is heterozygous, his phenotype is more consistent with homozygosity. The pseudogene PMS2CL sequence corresponds to exons 9 and $11-$ 15 of the $P M S 2$ gene [19]; and may be amplified by primers used for amplification of PMS2 exon 9. Therefore it is likely that IV.3's chromatogram illustrates sequence data from both $P M S 2$ and PMS2CL.

Patients with MMR-D and their families need heightened surveillance and we have recommended National Comprehensive Cancer Network practice guidelines for HNPCC/Lynch syndrome for IV.1 and her parents with the addition of annual upper endoscopy for IV.1. Since HNPCC or MMR-D cannot be excluded in the other siblings (IV.2, IV.4) similar surveillance was recommended for them as well until further information can be gained. Therapeutically it is important to develop chemotherapeutic agents that are relevant for these cancers since several in vitro studies have shown resistance of MMR-deficient cell lines to commonly used agents [20]. In conclusion, this case documents a novel mutation of PMS2, underscores the clinical traits of the pediatric cancer syndrome of MMR-D, emphasizes the clinical value of genetic testing, and highlights pediatric duodenal carcinoma as a sentinel cancer of MMR-D

\section{ACKNOWLEDGMENT}

This work is supported (in part) by the National Institutes of Health through the University of Michigan's Cancer Center Support Grant (5 P30 CA46592), NCI R01 CA81488 (SBG), the University of Michigan Cancer Genetics Registry, and NRSA [5 T32 HD007513-11] (SR). We are grateful to the patient and her parents for participating in this study, and to Drs. James D. Geiger and Mark Zalupski for their help in her clinical management.

\section{REFERENCES}

1. Maehara Y, Egashira A, Oki E, et al. DNA repair dysfunction in gastrointestinal tract cancers. Cancer Sci 2008;99:451-458.

2. Felton KE, Gilchrist DM, Andrew SE. Constitutive deficiency in DNA mismatch repair. Clin Genet 2007;71:483-498.

3. Felton KE, Gilchrist DM, Andrew SE. Constitutive deficiency in DNA mismatch repair: Is it time for Lynch III? Clin Genet 2007;71:499-500

4. Wimmer K, Etzler J. Constitutional mismatch repair-deficiency syndrome: Have we so far seen only the tip of an iceberg? Hum Genet 2008;124:105-122.

5. Ricciardone MD, Ozcelik T, Cevher B, et al. Human MLH1 deficiency predisposes to hematological malignancy and neurofibromatosis type 1. Cancer Res 1999;59:290-293.

6. Wang Q, Lasset C, Desseigne F, et al. Neurofibromatosis and early onset of cancers in hMLH1-deficient children. Cancer Res 1999; 59:294-297.

7. Lindor NM, Burgart LJ, Leontovich O, et al. Immunohistochemistry versus microsatellite instability testing in phenotyping colorectal tumors. J Clin Oncol 2002;20:1043-1048.

8. Senter L, Clendenning M, Sotamaa K, et al. The clinical phenotype of Lynch syndrome because of germ-line PMS2 mutations. Gastroenterology 2008;135:419-428.

9. Gallinger S, Aronson M, Shayan K, et al. Gastrointestinal cancers and neurofibromatosis type 1 features in children with a germline homozygous MLH1 mutation. Gastroenterology 2004;126:576585 .

10. Agostini M, Tibiletti MG, Lucci-Cordisco E, et al. Two PMS2 mutations in a Turcot syndrome family with small bowel cancers. Am J Gastroenterol 2005;100:1886-1891.

11. Murphy HR, Taylor W, Ellis A, et al. An unusual case of Turcot's syndrome associated with ileal adenocarcinoma, intestinal nonHodgkin's lymphoma, and duodenal adenocarcinoma. Review of the classification and genetic basis of Turcot's syndrome. Fam Cancer 2005;4:139-143

12. Will O, Carvajal-Carmona LG, Gorman P, et al. Homozygous PMS2 deletion causes a severe colorectal cancer and multiple adenoma phenotype without extraintestinal cancer. Gastroenterology 2007;132:527-530.

13. Alotaibi H, Ricciardone MD, Ozturk M. Homozygosity at variant MLH1 can lead to secondary mutation in NF1, neurofibromatosis type I and early onset leukemia. Mutat Res 2008;637:209-214.

14. Wang Q, Montmain G, Ruano E, et al. Neurofibromatosis type 1 gene as a mutational target in a mismatch repair-deficient cell type. Hum Genet 2003;112:117-123.

15. Plaschke J, Linnebacher M, Kloor M, et al. Compound heterozygosity for two MSH6 mutations in a patient with early onset of 
HNPCC-associated cancers, but without hematological malignancy and brain tumor. Eur J Hum Genet 2006;14:561-566.

16. Scott RH, Mansour S, Pritchard-Jones K, et al. Medulloblastoma, acute myelocytic leukemia and colonic carcinomas in a child with biallelic MSH6 mutations. Nat Clin Pract Oncol 2007;4:130-134.

17. Rahner N, Hoefler G, Hogenauer C, et al. Compound heterozygosity for two MSH6 mutations in a patient with early onset colorectal cancer, vitiligo and systemic lupus erythematosus. Am J Med Genet A 2008;146A:1314-1319.
18. Etzler J, Peyrl A, Zatkova A, et al. RNA-based mutation analysis identifies an unusual MSH6 splicing defect and circumvents PMS2 pseudogene interference. Hum Mutat 2008;29:299-305.

19. Hayward BE, De Vos M, Valleley EM, et al. Extensive gene conversion at the PMS2 DNA mismatch repair locus. Hum Mutat 2007;28:424-430.

20. Fedier A, Fink D. Mutations in DNA mismatch repair genes: Implications for DNA damage signaling and drug sensitivity (review). Int J Oncol 2004;24:1039-1047.

\title{
KIR-HLA Receptor-Ligand Mismatch Associated With a Graft-Versus-Tumor Effect in Haploidentical Stem Cell Transplantation for Pediatric Metastatic Solid Tumors
}

\author{
Antonio Pérez-Martínez, MD, PhD, ${ }^{1 *}$ Wing Leung, MD, $\mathrm{PhD},{ }^{2}$ Evangelina Muñoz, ${ }^{1}$ Rekha lyengar, $\mathrm{PhD},{ }^{2}$ \\ Manuel Ramírez, $\mathrm{MD}$, $\mathrm{PhD},{ }^{1}$ José Luis Vicario, $\mathrm{PhD}^{3}{ }^{3}$ Álvaro Lassaletta, $\mathrm{MD},{ }^{1}$ Julián Sevilla, $\mathrm{MD}, \mathrm{PhD},{ }^{1}$ \\ Marta González-Vicent, MD, PhD, ${ }^{1}$ Luis Madero, MD, PhD, ${ }^{1}$ and Miguel Ángel Díaz-Pérez, MD, PhD ${ }^{1}$
}

Killer immunoglobulin-like receptors (KIRs) on natural killer cells (NKs) recognize groups of human leukocyte antigen (HLA) class I alleles. Cells without an inhibitory HLA ligand may trigger NK activation. Reduced risk of relapse has been reported in malignant hematologic diseases after haploidentical transplantation when HLA ligands against the inhibitory KIRs present in the donor were absent in the recipient. We performed haploidentical transplant in three children with refractory solid tumors. Our results showed that beneficial antitumor effects could be observed in the presence of inhibitory KIR-HLA mismatch. These preliminary results suggest a possible association between disease control and NK cell alloreactivity. Pediatr Blood Cancer 2009;53:120-124.

(c) 2009 Wiley-Liss, Inc.

Key words: haploidentical stem cell transplantation; KIR-HLA mismatch; NK cells; pediatric solid tumors

\section{INTRODUCTION}

Little progress has been made in the survival of children with metastatic and refractory solid tumors [1]. Allogeneic hematopoietic stem cell transplantation (HSCT) has been proposed as a potential curative alternative in patients with refractory malignancies [2]. A possible graft-versus-tumor (GVT) effect has been documented in children with metastatic and relapsed Ewing sarcoma [3], neuroblastoma [4], melanoma [5], and hepatoblastoma [6]. However, the immunological mechanisms that mediate the GVT effect have not been elucidated. Early immune reconstitution after a conditioning regimen is led by natural killer (NK) cells, and for several weeks, they represent the only detectable lymphoid population. NK cell alloreactivity in vitro may be predicted by the lack of ligands for inhibitory killer immunoglobulin-like receptors (KIRs) [7]. Inhibitory KIRs bind with four specificities for polymorphic human leukocyte antigen (HLA) class I molecules. NK cell reactivity may be further enhanced by a Th1 cytokine environment and by T-cell lymphopenia [8,9].

To evaluate the potential of NK cell-mediated GVT effect and its immunological mechanisms, we performed a pilot study of haploidentical HSCT in three children with refractory tumors with no known cure.

\section{METHODS}

\section{Patients and Transplantation}

The study involved three patients with metastatic solid tumors that were refractory to chemotherapy (Table I). This study was approved by the Ethical Committee of Hospital Niño Jesús. Informed consent was obtained in accordance with the
Helsinki Declaration. HSCT was performed using parental CD3/ CD19 depleted G-CSF mobilized peripheral blood. Reducedintensity conditioning consisted of busulfan ( $4 \mathrm{mg} / \mathrm{kg} / \mathrm{day}, 2$ days), fludarabine (30 mg/m²/day, 5 days), thiotepa ( $5 \mathrm{mg} / \mathrm{kg} /$ day, 2 days), and methylprednisolone $(4 \mathrm{mg} / \mathrm{kg} /$ day, 5 days $)$. Methotrexate $\left(15 \mathrm{mg} / \mathrm{m}^{2} /\right.$ day, day +1 , and $10 \mathrm{mg} / \mathrm{m}^{2} /$ day, days +3 and +6$)$ and cyclosporine $(3 \mathrm{mg} / \mathrm{kg} /$ day, day -1 until 1 month after the infusion) were also administered. Immune reconstitution and hematopoietic chimerism were assessed monthly after HSCT. Computed tomography and magnetic resonance imaging were performed before and 3 months after HSCT.

\section{HLA Typing and KIR Genotyping, Phenotyping, and Cytotoxicity}

HLA-C allotypes ( $\mathrm{C} 1$ and $\mathrm{C} 2$ ) and HLA-B allotypes (Bw4) were determined using high-resolution polymerase chain reaction-

\footnotetext{
${ }^{1}$ Department of Pediatric Hematology and Oncology, Hospital Niño Jesús, Universidad Autónoma de Madrid, Madrid, Spain; ${ }^{2}$ Department of Oncology, St. Jude Children's Research Hospital, Memphis, Tennessee; ${ }^{3}$ Laboratorio de Histocompatibilidad y Biología Molecular, Centro de Transfusión de Madrid, Madrid, Spain

Grant sponsor: Spanish National Health Service; Grant number: FIS CM-04/00011.

*Correspondence to: Antonio Pérez-Martínez, Servicio de Oncología y Trasplante del Hospital Infantil Universitario Niño Jesús, Menéndez Pelayo 69, Madrid 28009, Spain.

E-mail: aperezm.hnjs@salud.madrid.org
}

Received 7 November 2008; Accepted 6 January 2009 